\title{
Pitiríase Liquenoide e Varioliforme Aguda: Sucesso Terapêutico com Doxiciclina
}

\author{
Lichenoid and Acute Varioliform: \\ Therapeutic Success with Doxycycline
}

Luciana Rebouças de Araujo ${ }^{1}$, Flávia Silva Bastos ${ }^{1}$, Hyndiara Lorena Frota Oliveira ${ }^{1}$, Ariene Pedreira Paixão ${ }^{1}$, Jussamara Brito Santos ${ }^{1}$, Enio Maynard Barreto ${ }^{1 *}$

${ }^{1}$ Hospital Santa Izabel; Salvador, Bahia, Brazil

Correspondence addresses:

Dr. Enio Maynard Barreto ermbarreto@terra.com.br

Received: August 9, 2021

Revised: August 20, 2021

Accepted: August 25, 2021

Published: September 30, 2021

Data Availability Statement: All relevant data are within the paper and its Supporting Information files.

Funding: This work was the result of authors' initiative. There was no support of research or publication funds.

Competing interests: The authors have declared that no competing interests exist.

Copyright

(C) 2021 by Santa Casa de Misericórdia da Bahia.

All rights reserved.

ISSN: 2526-5563

DOI: 10.35753
A pitiríase liquenoide representa um grupo de doenças inflamatórias que inclui: pitiríase liquenoide e varioliforme aguda (PLEVA), doença de MuchaHabermann (subtipo grave) e pitiríase liquenóide crônica. O diagnóstico é clínico e histopatológico. Diversos tratamentos têm sido utilizados. No entanto, a interpretação dos resultados é limitada pela pequena quantidade de casos descritos e frequente remissão espontânea. Neste trabalho, apresenta-se um caso de PLEVA tratado com doxiciclina. Homem, 26 anos, com erupção cutânea generalizada há 1 mês, compatível clínica e histopatologicamente com o diagnóstico de PLEVA. Sem reposta ao uso de corticoide, apresentou melhora importante após introdução de Doxiciclina. PLEVA é uma dermatose pouco comum, que pode evoluir para forma potencialmente fatal. $O$ tratamento de primeira linha inclui o uso de tetraciclina e eritromicina. Dapsona e prednisona são reservados para doença resistente ou severa. No caso apresentado, observouse boa resposta com doxiciclina.

Palavras-chave: Pitiríase Liquenoide; Doxiciclina; Tratamento.

Pityriasis lichenoides represents a group of inflammatory diseases which include pityriasis lichenoides, and acute varioliformis (PLEVA), Mucha-Habermann disease (severe subtype), and chronic pityriasis lichenoides. Diagnosis is clinical and histopathological. Many treatments have been used. However, the interpretation of the results is insufficient by the small number of cases described and frequent spontaneous remission. In this work, we report a case of PLEVA treated with doxycycline. A 26-year-old male with a generalized rash for one month, clinically and histopathologically compatible with a diagnosis of PLEVA. With no response to the use of corticosteroids, he showed significant improvement after the introduction of doxycycline. PLEVA is an uncommon dermatosis that can develop into a potentially fatal form. First-line treatment includes the use of tetracycline and erythromycin. Dapsone and prednisone are restricted for resistant or severe disease. In the present case, we observe a good response with doxycycline.

Keywords: Pityriasis Lichenoides; Doxycycline; Treatment.

\section{Introdução}

A pitiríase liquenoide (PL) representa um grupo de doenças inflamatórias com espectro variável que inclui: pitiríase liquenoide e varioliforme aguda (PLEVA), doença de Mucha-Habermann ulceronecrótica febril e 
pitiríase liquenoide crônica (PLC). ${ }^{1-4}$ É uma dermatose pouco comum, que se manifesta mais frequentemente na $2^{\mathrm{a}}$ e $3^{\mathrm{a}}$ décadas de vida, ${ }^{1,2}$ podendo acometer crianças em até $20 \%$ dos casos. $^{5}$ Revisões bibliográficas recentes não reportam predileção por sexo. ${ }^{1}$ Sua etiologia permanece incerta, no entanto, são aceitas três teorias para explicar a patogênese da PL. A primeira delas sugere tratar-se de uma reação inflamatória desencadeada por estímulos antigênicos, como agentes infecciosos (HIV, CMV, EBV, parvovírus B19, T. gondii, Mycoplasma e Staphylococcus), ${ }^{1-3}$ drogas (terapia hormonal, quimioterápicos, contraste iodado) e vacina (tríplice viral). ${ }^{1}$ A segunda hipótese propõe um distúrbio linfoproliferativo clonal de células T. ${ }^{1}$ Por fim, alguns autores sugerem um componente de vasculite mediada por imunocomplexos. ${ }^{1}$ Clinicamente, a forma aguda caracteriza-se pelo rápido aparecimento de pápulas eritematosas e vesico-pústulas que sofrem necrose central, com duração de semanas a meses. ${ }^{1,2}$ Acomete principalmente o tronco e região flexora dos membros. ${ }^{2}$ Podem estar presentes sinais sistêmicos, como febre e linfadenopatia. ${ }^{1,2}$ A Doença de MuchaHabermann é considerada uma variante grave da PLEVA, caracterizada por lesões ulceronecróticas na pele e mucosas, associadas a febre alta e manifestações sistêmicas que podem levar ao óbito. ${ }^{2-4}$ Diversas modalidades terapêuticas têm sido utilizadas, no entanto, a interpretação dos resultados é limitada devido à pequena quantidade de casos descritos (Figuras $1-4) .{ }^{1,4}$

\section{Relato de Caso}

Homem, 26 anos, previamente hígido, com pápulas e placas, em alvo, disseminadas (poupando palmas e plantas e mucosas oral e ocular), há 1 mês, que evoluíram com necrose central e crostas aderidas, pústulas. Apresentava picos febris. Referiu uso de Epocler ${ }^{\circledR} 3$ dias antes e negou quadros infecciosos prévios. Foi admitido com suspeita de eritema polimorfo e introduzida prednisona $1 \mathrm{mg} / \mathrm{Kg} / \mathrm{d}$, além de ceftriaxone $2 \mathrm{~g} / \mathrm{dia}$, por suspeita de infecção bacteriana secundária. Exames complementares demonstraram aumento de transaminases $(\mathrm{TGO}=51 / \mathrm{TGP}=194)$ e VHS de 32 , com demais exames laboratoriais sem alterações. Sorologias para hepatites B e C, HIV, HTLV, varicela-zoster IgM, VDRL, FAN e hemoculturas foram negativas. A histopatologia com imunohistoquímica evidenciou numerosos queratinócitos apoptóticos, degeneração vacuolar da camada basal e infiltrado inflamatório predominantemente $\mathrm{T}\left(\mathrm{CD} 8^{+}\right)$na derme, além de numerosas hemácias extravasadas.

Sem melhora do quadro com corticoterapia e feito o diagnóstico clínico e histopatológico de PLEVA, foi iniciada Dapsona $100 \mathrm{mg} /$ dia. O paciente cursou com anemia hemolítica, sendo substituída a medicação por Doxiciclina200mg/ dia. Evoluiu com melhora do quadro, recebendo alta 10 dias após o início da Doxiciclina, que foi mantida por 8 semanas, associado ao desmame da prednisona.

\section{Discussão}

O diagnóstico definitivo de PLEVA pode ser difícil e é corroborado pela clínica e histopatologia. ${ }^{2}$ As alterações mais comuns incluem infiltrado linfocitário, extravasamento de hemácias e necrose de queratinócitos. ${ }^{1-3}$

A imunohistoquímica é útil, evidenciando predomínio de linfócitos $\mathrm{T} \quad \mathrm{CD}^{+}{ }^{+}, 3 \quad$ Seu diagnóstico diferencial mais importante, a Papuloselinfomatoide, pode ser afastado pela ausência de células $\mathrm{CD} 30^{+} .{ }^{3}$ Com exceção da variante ulceronecrótica febril, a PLé geralmente considerada uma desordem benigna e de curso auto-limitado que, no entanto, pode ser encurtado pela terapia. ${ }^{2}$ Por outro lado, alguns autores acreditam que haja potencial de malignização, com possível progressão para linfoma cutâneo de células $T^{1,2}$

$\mathrm{O}$ tratamento de primeira linha inclui o uso de antibióticos orais, mais comumente 
Figura 1. Lesões em alvo, no inicio do quadro.

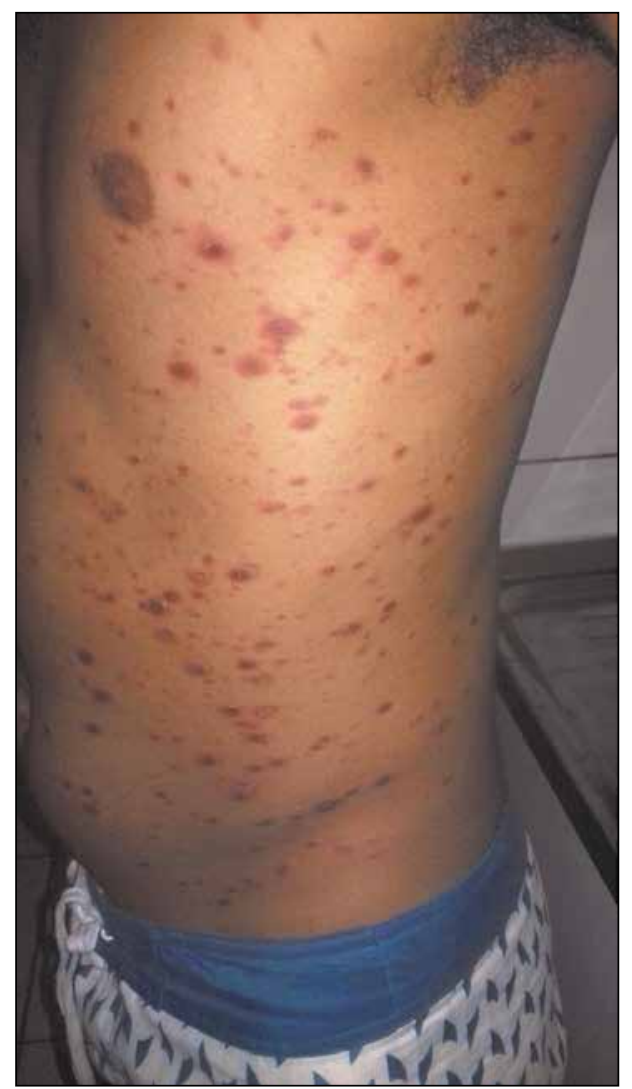

Figura 2. Evolução das lesões, com surgimento de crostas necróticas aderidas.

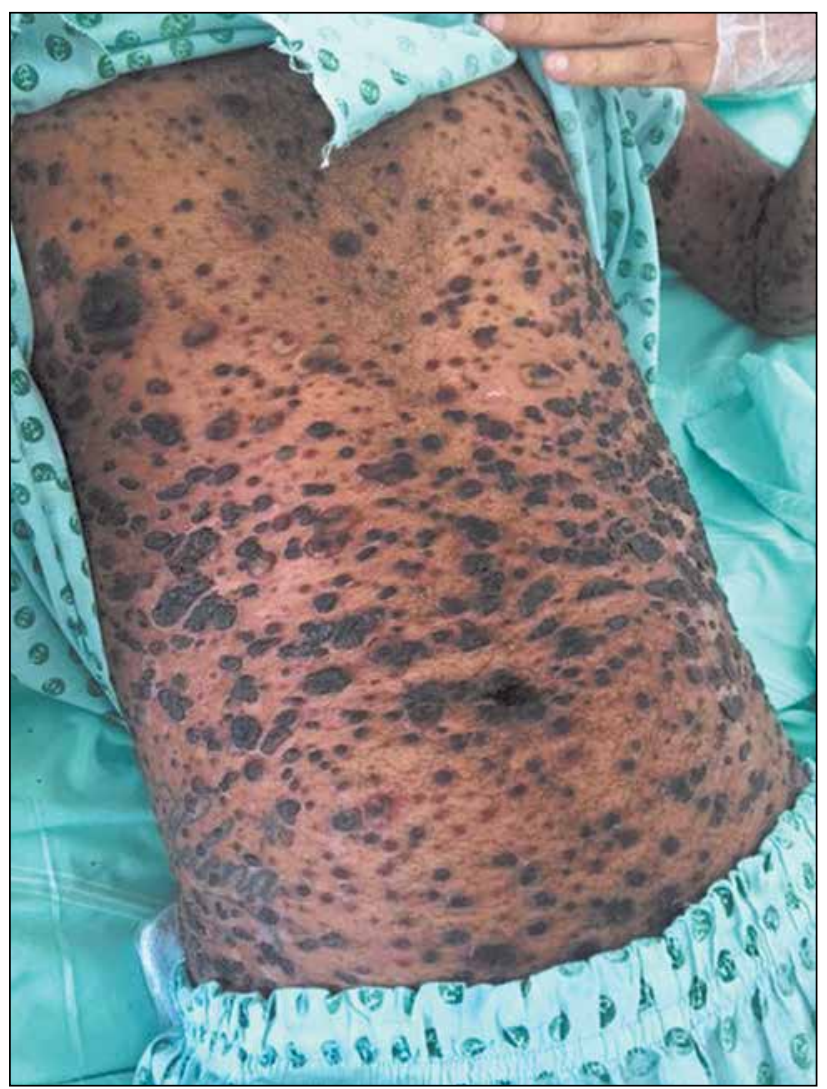

Figura 3. Dermatite de interface, com presença de numerosos queratinócitos apoptóticos. Vê-se ainda paraceratose, epongiose e numerosas hemácias extravasadas (H\&E).

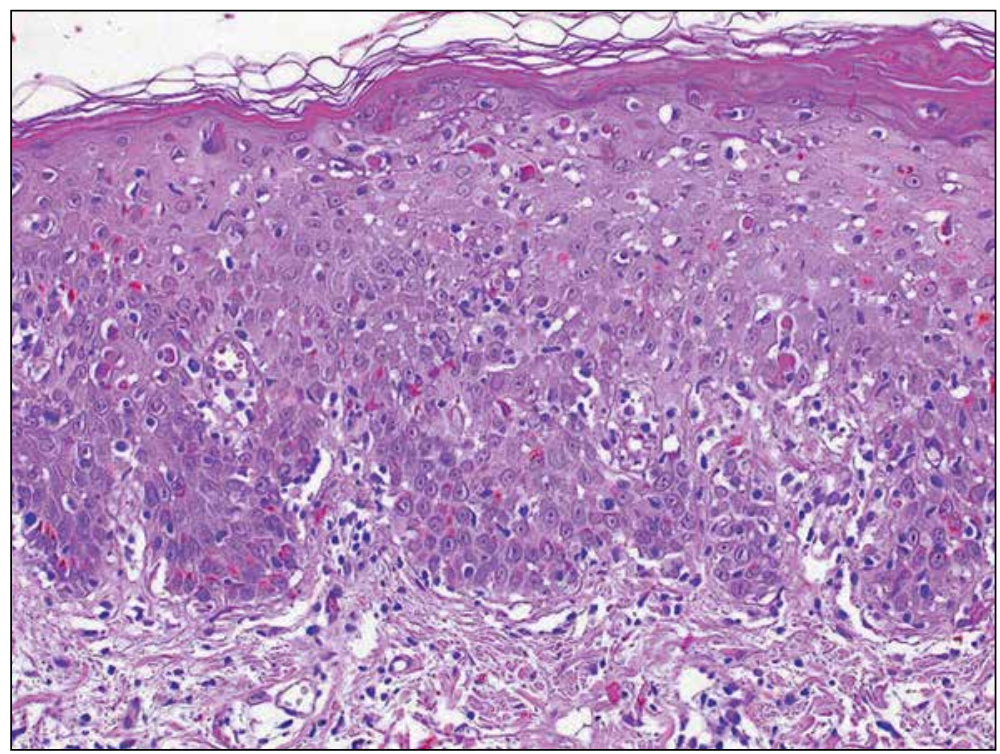

www.revistacientifica.hospitalsantaizabel.org.br 
Figura 4. Cicatrizes varioliformes residuais

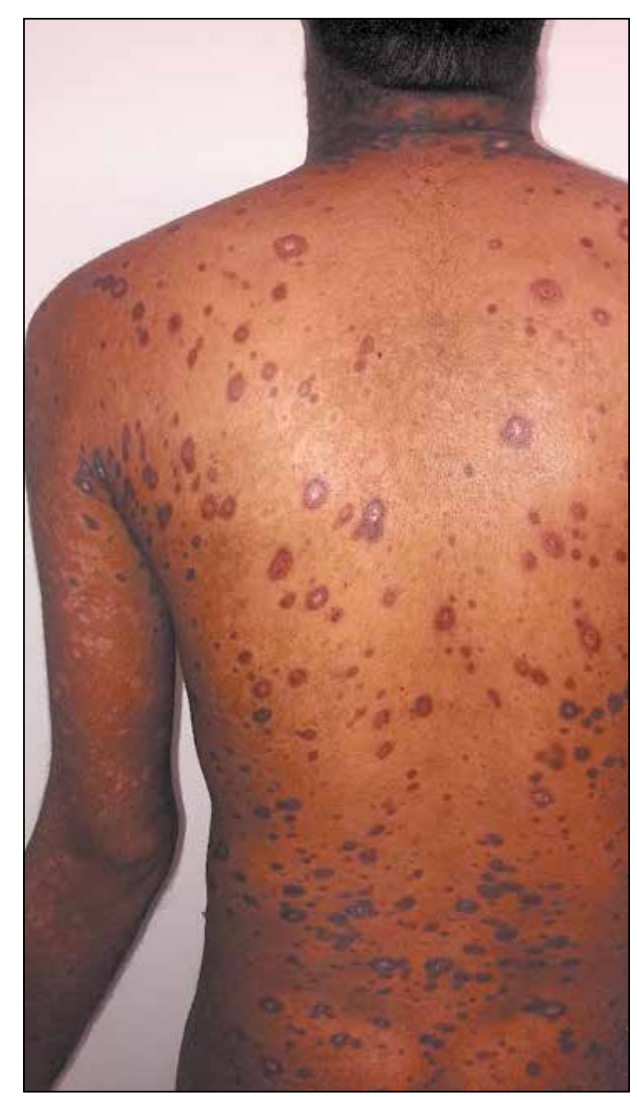

tetraciclina (1-2g/dia) e eritromicina (1-2g/dia), pelo período de 2 a 4 semanas. ${ }^{1-3}$ Corticoides tópicos e inibidores da calcineurina podem ser usados para diminuir o prurido, mas não alteram o curso da doença. ${ }^{2}$ Fototerapia é usada como segunda linha, especialmente útil na prevenção de recidivas, que tendem a ser comuns. ${ }^{2}$ Metotrexato, dapsona, ciclosporina, prednisona e retinoides são indicados como terceira linha, reservados para doença resistente ou severa. ${ }^{1-3}$ No caso apresentado, não foi observada melhora clínica com uso de prednisona ou dapsona. À doxiciclina houve boa resposta, com melhora significativa do quadro.

O tratamento da PLEVA pode constituir um desafio por tratar-se de uma doença auto-limitada e ainda sem terapêutica comprovadamente eficaz. Sua rara ocorrência e as dificuldades associadas ao seu manejo reforçam a importância do relato.

Ressalta-se a importância do seu diagnóstico pelo risco de evolução para a forma grave, geralmente precedida pelas lesões cutâneas da PLEVA. ${ }^{4}$ Além disso, devido à associação com desenvolvimentodedesordenslinfoproliferativas, é recomendado o acompanhamento regular desses pacientes. ${ }^{1}$

\section{Referências}

1. Bowers S, Warshaw EM. Pityriasislichenoides and its subtypes. J Am Acad Dermatol. 2006;55:557-572.

2. Fernandes NF, Rozdeba PJ, Schwartz RA, Kihiczak G, Lambert WC. Pityriasis lichenoides et varioliformisacuta: A disease spectrum. Int $\mathrm{J}$ Dermatol. 2010;49:257-261.

3. Pereira N, Brinca A, Brites MM, Julião MJ, Tellechea $\mathrm{O}$, Gonçalo M. Pityriasis lichenoides et varioliformis acuta: Case report and literature review. Case Rep Dermatol. 2012;4:61-65.

4. Bica BERG, Barros MGCRM, Junior CS. Doença de Mucha-Habermann. Rev Bras Reumatol. 2013;53:314-317.

5. Maranda EL, Smith M, Nguyen AH, et al. Phototherapy for pityriasis lichenoides in the pediatric population: A review of the published literature. Am J Clin Dermatol. 2016;17:583. 